\title{
Cloud Computing - A market Perspective and Research Directions
}

\author{
Amol C. Adamuthe, Vikram D. Salunkhe, Seema H. Patil \\ Rajarambapu Institute of Technology, Sangli, MS, India \\ E-mail: amol.admuthe@gmail.com \\ Gopakumaran T. Thampi \\ Dept. of IT, TSEC, Bandra, Mumbai, MS, India \\ E-mail: gtthampi@yahoo.com
}

\begin{abstract}
Computational paradigm has been revolving round cloud computing and its offshoots for some time and till we see a breakout resulting in a breakthrough technology driven by advances in microelectronics and material technology. Till we experience a radically efficient technology for computation it is worth juxtaposing the virtues of cloud computing and market's longing for offering cost and quality arbitrage to the marketplace. Integration of cloud computing in enterprises has the potential to influence the way business gets carried out by them in the market place. Different reports show that demand for cloud computing products and processes is in an upward growth trajectory. This paper identified the characteristics, drivers and constraints of cloud computing which influence its adaptation and integration in enterprises. We are also examining India specific opportunities and threats of cloud computing tools and cloud driven practices in the context of fierce competition among enterprises to remain competitive in the marketplace by reducing software licensing fees, cost of capital to acquire digital systems and cost of maintenances.

New directions in cloud computing are analyzed by using Gartner strategic technologies and trend in research publications. Paper focuses on exploring the research issues which are categorized into technical and business in nature for understanding the evolving fortunes of cloud computing. Number of papers published in IEEE is an indication of the popularity and relevance of the continued research initiatives happening in the area. It is also noticed that that very few researchers are attempting to understand the possibility of remodeling business processes leveraging the new found computational paradigm.
\end{abstract}

Index Terms-Cloud computing, market perspective, drivers, constraints.

\section{INTRODUCTION}

Cloud computing can be thought of as the successor of grid computing. In reality, it embodies aspects of mainframe, cluster and grid computing [1]. Cloud computing is a shifting of paradigm from old mainframe environment to the thin client based architecture [2]. Computing clouds are developed on large datacenters hosted by a single organization that provides services to others. These services are flexible, on demand and on a pay-per-use basis.

Cloud computing has received increasing interest from enterprises since its inception [3]. Recently cloud service providers are offering a wide range of solutions to businesses. Enterprise businesses are moving their IT services, applications and infrastructure to cloud-based architecture. According to IHS Technology, the market revenue in this segment will rise rapidly by a factor of three from 2011 to 2017 [4]. Cloud computing markets at $\$ 36$ billion in 2008 are expected to reach $\$ 160.2$ billion by 2015 [5]. Ovum Research forecasted the global cloud services market will reach revenues of $\$ 66$ billion in 2016 , with an annual growth rate of almost 30 per cent [6]. Research firm Forrester has projected public cloud services worth $\$ 14.7$ billion in 2010 will generate a sixfold increase in revenue for cloud vendors of $\$ 94.1$ billion by 2015 [6]. According to paper [7] wide adoption of cloud computing in a near future is unavoidable. The forecasted results from various reports show that cloud computing is growing rapidly.

Table 1 indicates the number of research publications in IEEE Xplore and ScienceDirect searched using keyword "Cloud Computing". This data is collected from the year 2006 to year 2014. The data is accessed in November 2014. The trend of number of papers published in IEEE Xplore and ScienceDirect is increasing.

Table 1. Research Publications (from 2006 to 2014) in IEEE Xplore and ScienceDirect for the "Cloud computing".

\begin{tabular}{|l|l|l|}
\hline Year & IEEE Xplore & ScienceDirect \\
\hline 2006 & 0 & 1 \\
\hline 2007 & 0 & 0 \\
\hline 2008 & 205 & 10 \\
\hline 2009 & 1103 & 104 \\
\hline 2010 & 2824 & 293 \\
\hline 2011 & 4650 & 618 \\
\hline 2012 & 6844 & 864 \\
\hline 2013 & 7576 & 1335 \\
\hline 2014 & 3969 & 1677 \\
\hline
\end{tabular}

Cloud computing has received attention by both industry professionals and researchers. Increasing interest 
of enterprises in cloud computing adoption creates need for analysis of cloud computing. This paper focus on cloud computing analysis by identifying internal characteristics and external factors. The analysis method is similar to strengths, weaknesses, opportunities and threats analysis. SWOT analysis was developed as a planning tool to understand strengths weaknesses, opportunities and threats involved in a project or business. In literature, primarily SWOT analysis is used to analyze the current situation of a technology, but the opportunities and threats can be used for technology forecasting [8].

Objective of this paper are

i) Explore cloud computing's capacity to offer cost and quality arbitrage to enterprises.

ii) Identify factors affecting cloud computing growth trajectory.

iii) Identify the opportunities and threats to cloud computing in India.

iv) Explores the new trends in cloud computing.

The rest of the paper is organized as follows: Section II is about related work. Cloud computing definitions and layered architecture is described in section III. Section IV of this paper illustrates market perspective of cloud computing. Section V is about opportunities and threats to cloud commuting in India. Cloud computing research directions are presented in section VI. Finally, the conclusions of our study are outlined in Section VII.

\section{RELATED WORK}

This section presents SWOT analysis / forecasting of various technologies.

Lobo and Khanna in [9], say that cloud model solution needs appropriate focus and opportunity in the Indian market. The research aims at examining the notion of cloud computing using SWOT analysis of the cloud computing services namely, SaaS, PaaS and IaaS.

Marston et al. in [10], identified the strengths, weaknesses, opportunities and threats for the cloud computing industry. According to authors, the biggest factor that impedes the adoption of the cloud computing paradigm is regulation at the local, national and international level. Cloud computing demands a coordinated response from governmental agencies.

Cole et al. in [11], assessed the strengths, weaknesses, opportunities and threats of various energy storage systems and discussed their applications on the generation and transaction level. SWOT analysis with respect to pumped hydro, CAES (Compressed Air Energy Storage), BES (Battery Energy storage), flywheels, SAES (Superconducting Magnetic Energy Storage) and supercapacitors. According to this research, pumped hydro, CAES and BES are technically and economically feasible.

Jandebeur et al. in [12], addressed the strengths, weaknesses, opportunities and threats of the near field communication (NFC) technology. This technology has a potential to be adopted in various industry sectors. For the customers, authors examined if the benefits of convenience and security are really worth the price of an NFC-enabled device. For the service provider, author examined if the benefits of convenience and security are worth the cost to set up the infrastructure for those devices to be used. According to authors the NFCequipped devices will replace the commonly used plastic card for convenience and security. NFC-enabled device will be used for all identification and financial transactions. Authors believe that companies can improve their efficiency and customer confidence by using NFC technology.

\section{Cloud COMPUTING}

Perception of different experts, providers and professionals about cloud computing is slightly differs. The National Institute of Standards and Technology (NIST) defined cloud computing as a "model for enabling ubiquitous, convenient, on-demand network access to a shared pool of configurable computing resources (e.g., networks, servers, storage, applications, and services) that can be rapidly provisioned and released with minimal management effort or service provider interaction" [13]. "Clouds are essentially large distributed computing facilities that make available their services to third parties on demand" [1].

Cloud hides the complex architecture on which it relies upon and provides to its users a single interface. Clouds are usually referred to as a large pool of computing and storage resources. These resources are abstract to end user. Fig. 1 shows the four layer architecture proposed in [14]. The fabric layer contains the raw hardware level resources, such as computing, storage and network. Unified resource layer virtualized the resources so that they can be exposed to upper layer and end users as integrated resources. The platform layer adds on a collection of specialized tools, middleware and services on top of the unified resources to provide a development and deployment platform. The application layer includes the applications that would run in the clouds [14].

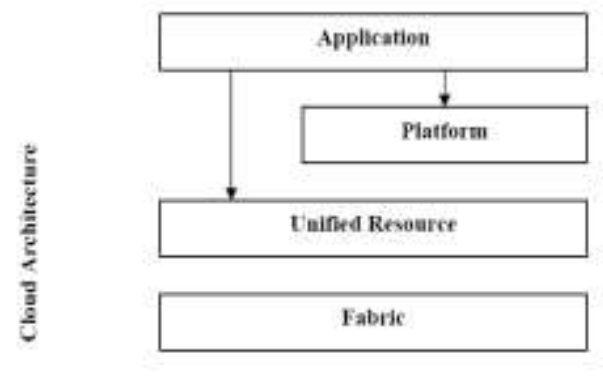

Fig.1. Four-layer architecture [14].

Different cloud computing service models are present such as Infrastructure as a Service- IaaS, Platform as a Service- PaaS, Software as a Service- SaaS, Management \& Monitoring as a Services- MMaaS, Testing as a Service- TaaS, Storage \& Database as a 
Service- SDaaS, Security as a Service-SeaaS, Integration as a Service- InaaS etc. Infrastructure as a Service, Platform as a Service and Software as a Service are three important service models. Cloud computing ontology proposed by [15] is depicted as five layers and shown in Fig. 2. This layered architecture represents the interdependency between the different layers in the Cloud.

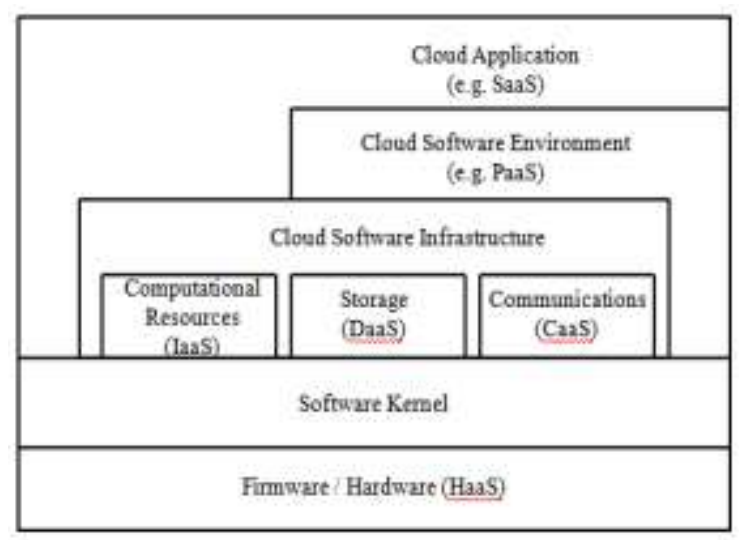

Fig.2. Cloud computing ontology [15].

\section{Cloud Computing - A Market Perspective}

In recent years cloud computing has a significant impact on all aspects of life. Enterprises require cloud computing for improvement in productivity and revenues. So, it is important for organizations to have insight into cloud computing technology and factors affecting on it's growth. This section illustrates cloud computing analysis based on market perspectives carried out using research papers, survey reports, white papers and case studies.

\section{A. Cloud Computing's Capacity to offer Cost and Quality Arbitrage in Real time Enterprise}

Table 2. Reasons of Cloud Computing Adoption.

\begin{tabular}{|l|l|}
\hline \multicolumn{1}{|c|}{ Drivers } & \multicolumn{1}{|c|}{ References } \\
\hline Business agility & {$[16,17,18]$} \\
\hline Improving business processes and tasks & {$[19]$} \\
\hline Ability to replace existing solutions & {$[20]$} \\
\hline Reducing IT infrastructure investment & {$[16,17,20]$} \\
\hline $\begin{array}{l}\text { Reducing IT management and maintenance } \\
\text { resources }\end{array}$ & {$[16,20]$} \\
\hline Reduce IT staff, Reduce IT risk & {$[20]$} \\
\hline Operational cost savings & {$[21]$} \\
\hline Increased productivity of IT & {$[16]$} \\
\hline Improving IT control & {$[16,20]$} \\
\hline $\begin{array}{l}\text { Increased capacity/availability (data center, } \\
\text { storage etc.) }\end{array}$ & {$[16,20]$} \\
\hline $\begin{array}{l}\text { Ability to obtain new resources quickly, } \\
\text { Ability to scale up and down quickly }\end{array}$ & {$[20,21]$} \\
\hline Pricing flexibility & {$[20,21]$} \\
\hline Disaster recovery / business continuity & {$[16,17]$} \\
\hline Resource optimization & {$[17]$} \\
\hline Energy efficiency, lower carbon footprint & {$[20]$} \\
\hline
\end{tabular}

Enterprises adopt cloud computing adoption as per company requirements. Few of the reasons of cloud computing adoption are summarized in Table 2. Many of the reasons are related with financial issues. Challenges in cloud computing adoption are summarized in Table 3. Challenges are technical, business related, market related and legal.

Table 3. Challenges in Cloud Computing Adoption.

\begin{tabular}{|l|l|}
\hline \multicolumn{1}{|c|}{ Constraints } & References \\
\hline No clear standards or lack of standards & {$[20,22]$} \\
\hline Market and technology immaturity & {$[22]$} \\
\hline Integration with existing systems & {$[21]$} \\
\hline $\begin{array}{l}\text { No clear procurement rules for } \\
\text { implementation, Difficulty in measuring ROI } \\
\text { of cloud solutions }\end{array}$ & {$[20]$} \\
\hline Comfort level of IT staff with cloud & {$[20,22]$} \\
\hline Risk of losing governance or control & {$[22,23]$} \\
\hline $\begin{array}{l}\text { Lack of clear value propositions, Complexity, } \\
\text { Reliability and high availability, }\end{array}$ & {$[22]$} \\
\hline Unclear licensing & {$[22,23]$} \\
\hline Legal issues & {$[23]$} \\
\hline $\begin{array}{l}\text { Interoperability i.e. difficulty in integrating } \\
\text { cloud solutions }\end{array}$ & {$[20]$} \\
\hline $\begin{array}{l}\text { Risk of vendor lock-in, } \\
\text { Insufficient data availability }\end{array}$ & {$[23]$} \\
\hline Cloud solutions are not secure enough & {$[20,23]$} \\
\hline
\end{tabular}

i) Technical and economical strengths of cloud computing

- Elasticity, On-demand services, Pay-per-use pricing model, Flexibility [24].

- Availability of a host of software systems on a 'pay for what you use' basis [7, 25, 26].

- Elastic and scalable computing infrastructure available 'on-demand' [7, 25, 26, 27]. The users can in practice access the cloud for services anytime from anywhere [7, 25].

- Cost effective, Flexible and innovative, Round the clock access, Simplified cost and consumption model, Faster provisioning of systems and application, Secured infrastructure, Compliant facilities, Flexible and resilient in disaster recovery, Reduces maintenance cost [28].

- Cloud computing has the possibilities to share software, hardware, information technological infrastructure through the virtualization [2]. The resources shared across multiple applications hosted in the cloud reduces it's cost [25, 27, 29].

- Reduction in capital expense of organizations as they need not invest in large computer infrastructure and repeatedly invest as computers become obsolete. Shifting CapEx to OpEx [7, 26, 27, 29].

- High availability - Applications can take advantage of a high availability architecture that minimizes or eliminates planned and unplanned downtime, improving user service levels and business continuity [27].

- Assured quality of service (QoS) based on service level agreements (SLA) which organizations can sign with providers [26].

- Backup and Recovery - Organizations can use cloud infrastructure to automatically back up their important data. This will allow quick recovery if 
data is corrupted [25, 26, 29].

- Ease of maintenance - The service provider takes care of the software maintenance [27, 29]. Reduction in IT staffing cost [29].

- Platform diversity - Cloud infrastructure offers support for a wide range of client platforms and operating systems [29].

- Faster development - Cloud can provide the basic infrastructure, operating systems and tools ondemand, thereby accelerating the development cycle, whereas we would spend a significant amount of time in setting up the basics in a traditional infrastructure [25, 27, 29].

- Almost unlimited storage - Storing information in the cloud gives you almost unlimited storage capacity [25].

\section{Advantages of Software as a Service}

- Global availability of SaaS applications through Internet.

- As most of the people are familiar with using the Internet, SaaS tends to have high adoption rates with lower learning curve [30, 31].

- Lower initial costs: Unlike traditional software application, SaaS applications are not purchased. SaaS applications are based on subscription. No license fees therefore, lower IT costs including hardware, software, and the persons needed to manage it [30].

- No burden of upgrades on customers: The traditional model for business applications required an upgrade and new investment in underlying technology and IT resources to take advantages of new features [31]. Because the SaaS provider manages all updates, there are no patches for customers to download and install [30]. This also removes the version compatibility that is found in traditional software that gets deployed on servers.

- Multitenant architecture: SaaS vendors with true multitenant architectures can scale indefinitely to meet customer demand [30].

\section{Advantages of Platform as a Service}

- Pre-built infrastructure - The infrastructure to run applications will be over the Internet. Developers do not need to worry about the storage and hosting and can focus on innovation and development.

- Faster development - PaaS vendors provide the pre-built functionality through APIs and user interfaces, so that users can avoid building everything from scratch. Hence, time to develop gets reduced.

- Richer functionality - Developers can enhance the overall functionality of the application by including the pre-integrated functionality such as search, analytics and reporting etc [32].

- Broad delivery option - PaaS solutions can be built to enable SaaS delivery to multiple OSs and devices such as mobile environments with little or no custom coding [32].

- Low budget - Building on-premise or traditional applications have always been expensive and complicated. PaaS is offered on demand with payas-you-go pricing. Customers are not required to do the capital investment.

- Scalability of applications - Deployed applications can scale over many thousands of users without any changes to the application.

\section{ii) Weaknesses or challenges of cloud computing}

- Data lock-in, Data segregation, Scaling resources, Data security and confidentiality, Data location, Deletion of data, Recovery and back-up, "Offline cloud" [33].

- On-demand access, Simplified application acceleration, scalability, Efficient resource allocation, Dynamic provisioning, Scalability, Fault tolerance, Trust [1].

- Need of expertise or training required in the field of cloud computing, Time and wealth constraints, Structure and environment, Adopting cloud based services means outsourcing, which may not be recommended for example, for library profession, Increases dependency, High speed Internet connection is required to connect to cloud, Integration with local hardware and software is difficult, Cloud computing needs adequate financial resources [28].

- Data transfer bottlenecks [34].

- Cloud service providers are not able to guarantee the location of a company's information on specified set of servers in a specified location [10].

- No clear common legal issues across nations and continents with respect to cloud computing data transfer.

- Most of cloud computing standards are under development [35, 36].

- Pricing schemes are different for various service providers [37]. No standard policies for defining the pricing for cloud services.

\section{B. Factors which boost up Cloud Computing Growth Trajectory}

According to reports published by McKinsey Global Institute, KPMG and NASSCOM, IDC, Gartner etc cloud computing will make a huge impact on enterprise, communities and societies in recent years. This subsection lists the factors which boost up cloud computing growth trajectory. The factors are categorized in technology development, market maturity, industry growth, government support, market need etc.

\section{iii) Current state of Cloud Computing in Hype-cycle}

The hype cycle model was developed by Jackie Fenn of Gartner. Hype cycle model express the level of the technology's maturity and the degree of its adoption and commercialization. Fig. 3 shows cloud computing hypecycle based on Gartner Hype-cycle. Peoples expectations describe the bell shape curve which shows the initial 
enthusiasm and disappointment arrived by positive and negative hype. In year 2013 and 2014 cloud technology is in trough of disillusionment phase. Cloud computing is moving fast through hype-cycle stages.

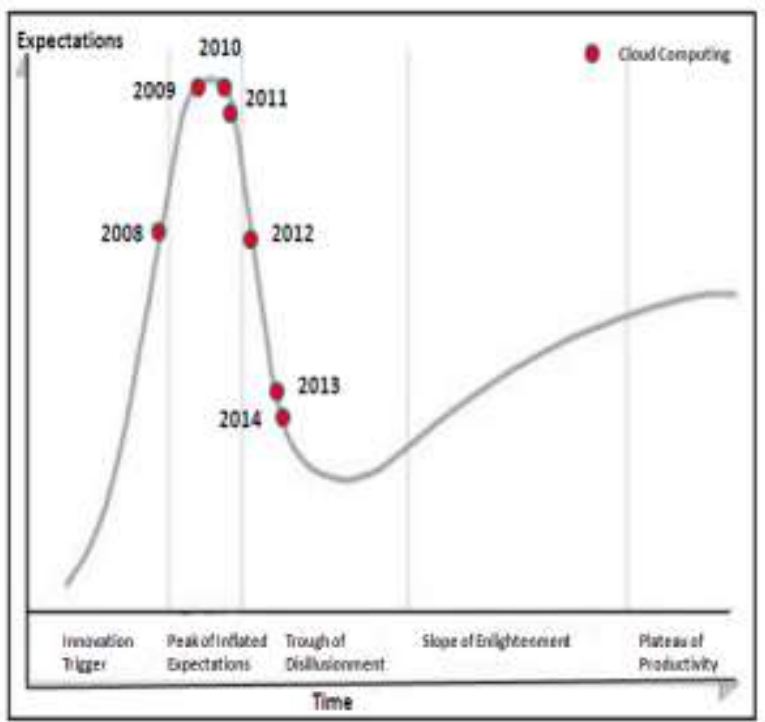

Fig.3. Cloud computing hype-cycle based on Gartner hype-cycle Source: (Gartner hype-cycle of cloud computing 2009, 2010, 2011 and 2012), (Gartner hype-cycle for emerging technology 2008, 2013 and 2014)

\section{iv) Relating Cloud Computing Hype-cycle and Life cycle}

Fig. 4 shows news articles, papers and patents of cloud computing. The term 'cloud computing' is used as keywords in the field of title to find out number of news article in Google trends, papers published in IEEE and ScienceDirect and patents filed in U.S. patents office and Espacenet. Increase in number of papers and patents indicates that engineering and business knowledge in cloud computing is increasing very fast. This increases the probability of success of cloud computing in market place.

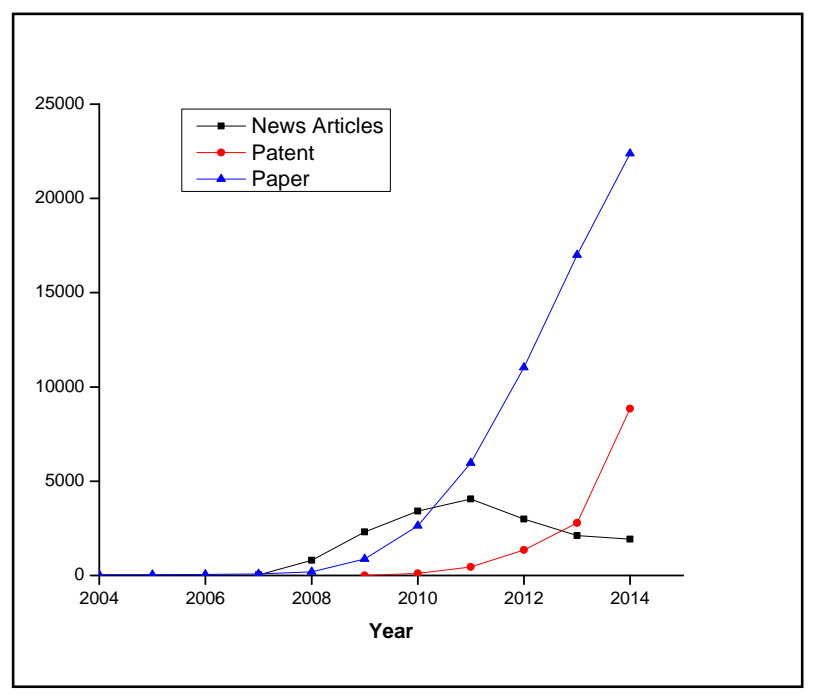

Fig.4. Cloud computing hype-cycle and lifecycle.

\section{v) Cloud computing Industry Evolution}

Fig. 5 shows the increase in number of cloud service providers. Increasing number of providers shall lead to increase in market competition. Market competition will lead to product innovations and cost reductions.

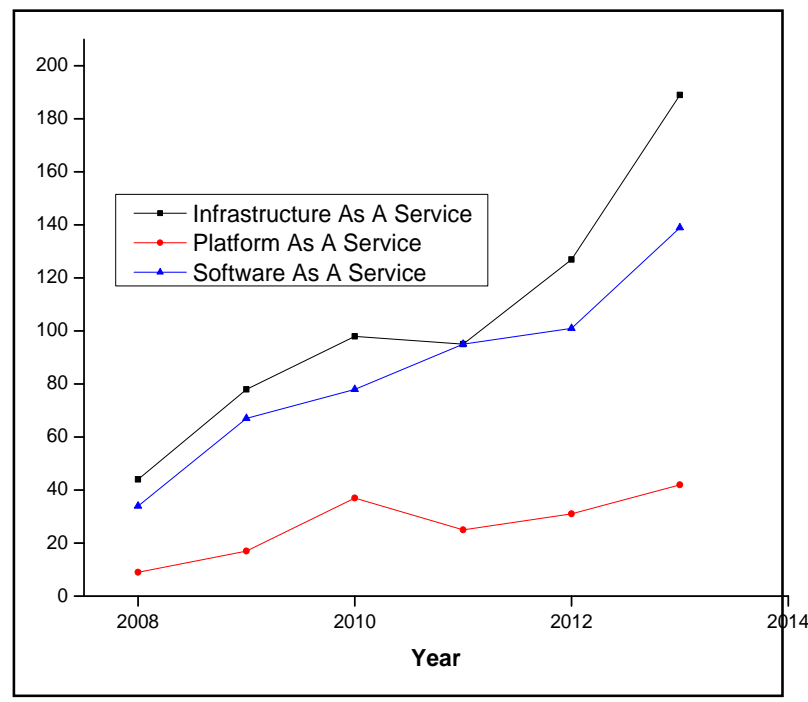

Fig.5. Cloud computing providers.

\section{vi) "S curve" of Computational Technologies}

Fig. 6 shows the actual cumulative IEEE Papers for selected computational technologies. Mainframes and minicomputers are relatively older technologies in computational technology family. Their growth is slow. Autonomic computing, cluster computing, grid computing and cloud computing are newer technologies. Very few historical data is available for these technologies. Progress rate of grid computing and cloud computing is much higher than other technologies.

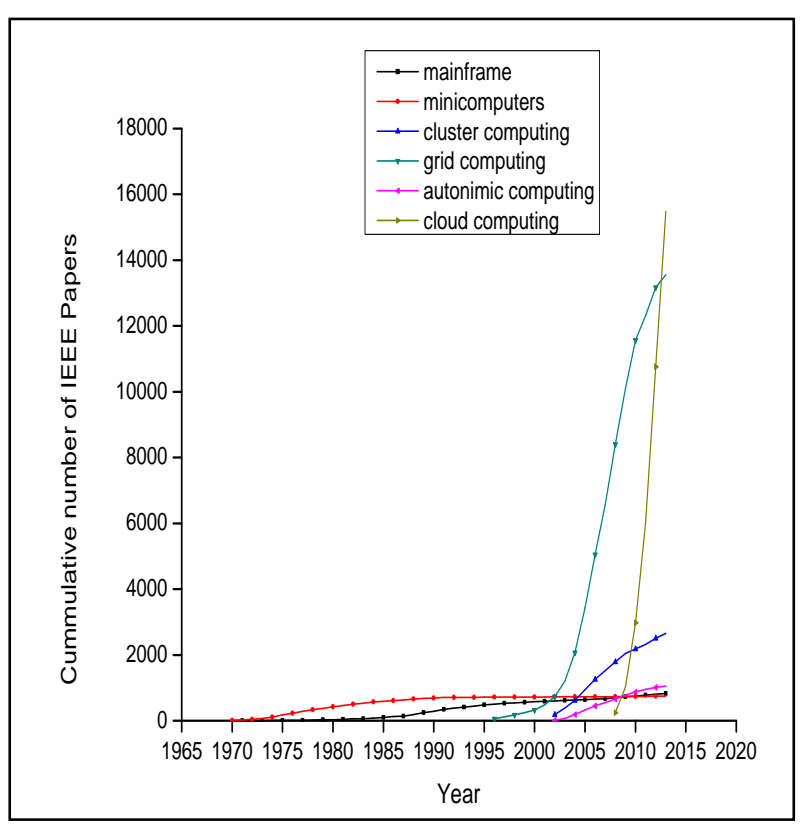

Fig.6. Actual Cumulative IEEE Papers for computational technologies. 
vii) Government Support

- Governments such as US, UK, Japan and Australia are encouraging for cloud computing adoption and development.

- In the recent years, the interest in cloud computing in the Asia Pacific region has grown exponentially.

- Cloud computing technology enables the governments and local firms to benefit from the effective use of information technology [10].

\section{viii) Market Growth}

- Giant enterprise such as Google, Amazon, Microsoft, Adobe, Oracle, RedHat etc. are making investment in cloud computing.

- Collaborations and acquisitions are happing between cloud providers and vendors.

- Many big enterprises are using cloud computing services for their business such as Coca-Cola Enterprises, Times newspaper, Mogulus TV channels, Animoto etc.

- Increasing support from hardware and software vendors to cloud computing.

ix) Prerequisite for Cloud Adoption

- Rising computer penetration, Improvement in bandwidth availability, Innovations in commodity server market, Improvements in storage technology [38].

- Different survey reports shows that user attitude towards cloud computing adoption is increasing.

x) Cloud Computing Technology Improvement

- Modern information services can be offered through cloud computing [28, 34].

- All time availability is possible through cloud computing [2].

- $\quad$ Adaptive to future needs [28, 34].

- High-technology work environment [28, 34].

- Strong experience and involvement in standardization efforts / process [28].

- Increase in knowledge base (patents and papers).

- Clouds computing architectures, service models, deployment models, security models are evolving very fast.

\section{xi) Market Need}

- Increasing, variable and quick demand for storage and computations from different applications and enterprises.

- Good opportunity for SMEs for making progress without worrying about the upfront investments [34].

- Increasing maintenance cost in traditional IT department of an enterprise. According to IDC report approximately 70 percent of an IT budget is spent on maintaining current IT infrastructures versus adding new capabilities.

- Need to increase utilization of hardware resources in distributed systems.

- Need of eco-friendly systems. Solution to minimize the use of servers due to it's high energy consumption.

- Marketplace enhancement in terms of functionality, innovation and price [34].

- Need of non-monopolistic business system.

- Cloud computing is suitable for big data and analytics.

C. Factors which adding up bottlneckness leading to resistance in breakthrough success of $C C$

- Heavy investment by enterprise in existing systems.

- Users of Internet are increasing tremendously which will lead to the data transfer bottlenecks and the available Internet bandwidth constraint issue may arise. Therefore large Internet bandwidth is big requirement.

- Third party service provider dependency is required for cloud computing [2].

- Lack of specific standard regulations (local, national and international) [34].

- Migration from one to another platform is difficult [28, 34].

- Hidden cost (backup, system recovery and problem solving) [28, 34].

Many of the threats listed above can be minimized by initiatives by researchers, providers and governments.

- Threat from inventions form physics, microelectronics and material science. Technologies in research such as quantum computing, autonomic computing and edge computing [39].

- Open source software movement can be threat for software as service.

\section{OPPORTUNITIES AND THREATS FOR CLOUD COMPUTING IN INDIA}

Worldwide cloud computing adoption in increasing very rapidly. India is not an exception for this. "In India, cloud services revenue is projected to have a five-year projected compound annual growth rate (CAGR) of 33.2 percent from 2012 through 2017 across all segments of the cloud computing market. Segments such as software as a service (SaaS) and infrastructure as a service (IaaS) have even higher projected CAGR growth rates of 34.4 percent and 39.8 percent," said Ed Anderson, research director at Gartner [40]. The research by IDC titled "Indian Cloud Market Overview 2011-2016" provides estimates that Indian cloud market will grow over $70 \%$ from 2014. This section illustrates the opportunities and threats for cloud computing in India.

\section{A. Opportunities}

- The Indian government's Digital India project provides potential opportunities for cloud adoption at a cost of $\$ 19$ billion between 2014-2018. 
- The Government of India is embracing cloud computing technology for expanding its egovernance initiatives throughout the country [41].

- Indian manufacturing sector has come a long way and the use of IT in manufacturing can be found since last over two decades. Since 2010, CIOs in Indian manufacturing have started adopting cloud models and this is highlighted in many research studies and industry circles [41].

- Government of India has embarked upon an ambitious initiative called GI Cloud also named MeghRaj. This decision has been taken to utilize and harness the benefits of cloud computing. The focus of this initiative is to accelerate delivery of e-services in the country while optimizing ICT spending of the government [42].

- Microsoft to invest Rs 1,400 crore in India cloud data centers. Microsoft Launches Cloud Accelerator Program for Indian Enterprises \& Government. TCS involved in putting data centers in India.

- Increased number of IT companies and ISPs in India.

- The key drivers for IT growth in India is highlighted by the growing acceptance of cloud based solutions, embracing merging technologies like Internet of Things (IoT), Big Data, mobile technologies $(3 \mathrm{G}, 4 \mathrm{G})$ and fuelled by Indian government's initiatives for a digital India.

\section{B. Threats}

- Data transfer bottlenecks and therefore the available network bandwidth constraint issue may arise.

- Poor connectivity [43] degrades the quality of service.

- Although the government of India has initiated the movement of using the cloud for e-governance applications, no common legal issues across India for cloud services.

- India is not yet economically strong therefore direct service cost and hidden cost (backup, system recovery and problem solving) $[28,34]$ may affect the adoption of cloud.

- No clear procurement rules for cloud implementation in India.

\section{NEW DiRECTIONS IN CLOUd COMPUTING}

This section discusses new directions in cloud computing based on trend in research publications in IEEE and Gartner strategic technologies.

\section{A. Research Publication Trend}

Although cloud computing can be thought of as a business model, this domain has too many research issues that need to be solved. Otherwise they may affect the adoption decision of cloud computing by the organizations.

As shown in the Fig. 7, the cloud computing research areas are classified into two categories namely, Technical Aspects and Business Aspects.

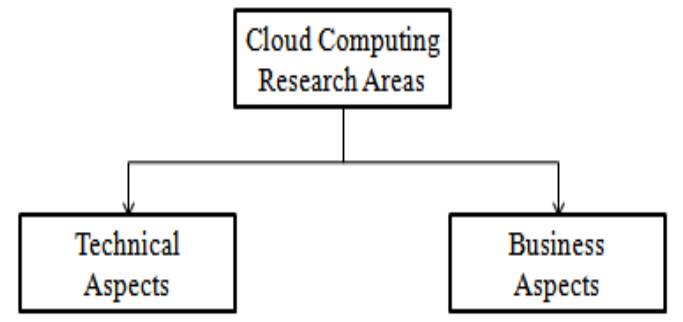

Fig.7. Classification of cloud computing research areas.

The research issues in cloud computing under technical aspects category are given in Table 4. This category of research areas includes the areas, which concentrates on the technical characteristics or attributes of cloud computing.

Research trends of cloud computing - technical aspects in IEEE are shown in Fig. 8. These trends indicate number of publications happed in each research area coming under the technical aspects category.

Table 4. Research issues in Cloud Computing - Technical Aspects.

\begin{tabular}{|l|l|}
\hline \multicolumn{1}{|c|}{ Technical Aspects } & \multicolumn{1}{c|}{ References } \\
\hline Security & {$[1,44,45,46,47,, 48$,} \\
& $49,50,51,52,53$, \\
& $54,55,56,57,58]$ \\
\hline Privacy & {$[1,44,47,57,59,60]$} \\
\hline Availability & {$[33,50,57]$} \\
\hline Reliability & {$[44]$} \\
\hline Virtualization & {$[51,53,61,62,63]$} \\
\hline Architecture & {$[64]$} \\
\hline Optimization & {$[61,65,66,64]$} \\
\hline Comparative study of Cloud with & {$[54]$} \\
previous technologies & \\
\hline Multi-tenancy & {$[65,67]$} \\
\hline Mobile Cloud computing & {$[68,69,70,71,72]$} \\
\hline Performance & {$[33,50,56,73]$} \\
\hline $\begin{array}{l}\text { Energy management / } \\
\text { Energy efficiency }\end{array}$ & {$[1,64,65,74]$} \\
\hline Interoperability & {$[1,54,61,75]$} \\
\hline Technical loss of control & {$[1,56]$} \\
\hline $\begin{array}{l}\text { Data Portability / Integration, } \\
\text { Software Compatibility }\end{array}$ & {$[56]$} \\
\hline $\begin{array}{l}\text { Open Source Usage, } \\
\text { Confidentiality, } \\
\text { Cloud Provider Malfeasance }\end{array}$ & {$[57]$} \\
\hline
\end{tabular}




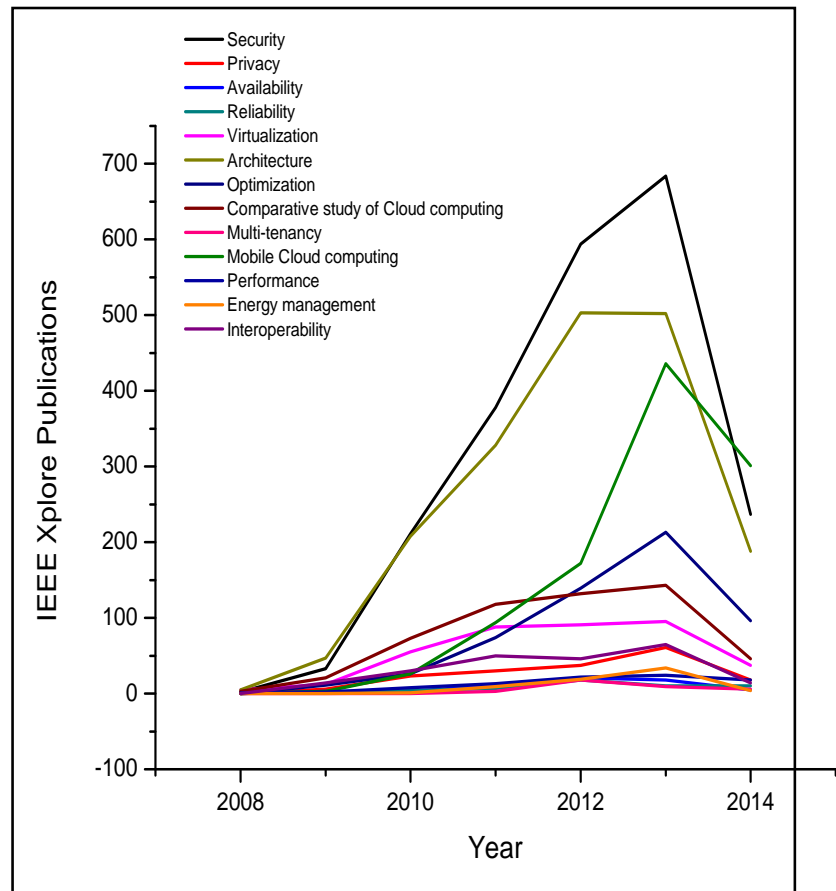

Fig.8. Research trend of Cloud Computing - Technical Aspects in IEEE Xplore.

The research issues in cloud computing under business aspects category are given in Table 5.

Table 5. Research trend of Cloud Computing - Business Aspects

\begin{tabular}{|l|l|}
\hline \multicolumn{1}{|c|}{ Business Aspects } & \multicolumn{1}{c|}{ References } \\
\hline Service level agreement (SLA) & {$[44,53,56,57,76,77]$} \\
\hline Licensing issues & {$[44,53,57]$} \\
\hline Billing / Pricing models & {$[1,78,79]$} \\
\hline Broker issues & {$[80]$} \\
\hline Standards and Cloud policies & {$[54]$} \\
\hline Total cost of ownership (TCO) & {$[81]$} \\
\hline Energy management & {$[64,65,74]$} \\
\hline Adoption & {$[3,7,61,82,83,84,85,86$,} \\
& $87,88]$ \\
\hline Organizational loss of control & {$[56]$} \\
\hline Lock-In Challenges & {$[56,57]$} \\
\hline Legislation & {$[1]$} \\
\hline Privilege abuse & {$[33]$} \\
\hline Cost Efficiency & {$[57,58]$} \\
\hline
\end{tabular}

Research trends of cloud computing - business aspects in IEEE are shown in Fig. 9. These trends indicate for each year, number of publications happed in each research area coming under the business aspects category.

Table 6 illustrates the percentage of cloud computing research studies (IEEE Xplore publications) carried out in the technical and business aspects categories. Percentage ratios from 2008 to 2014 (November end) indicate that the technical research dominates the business research.

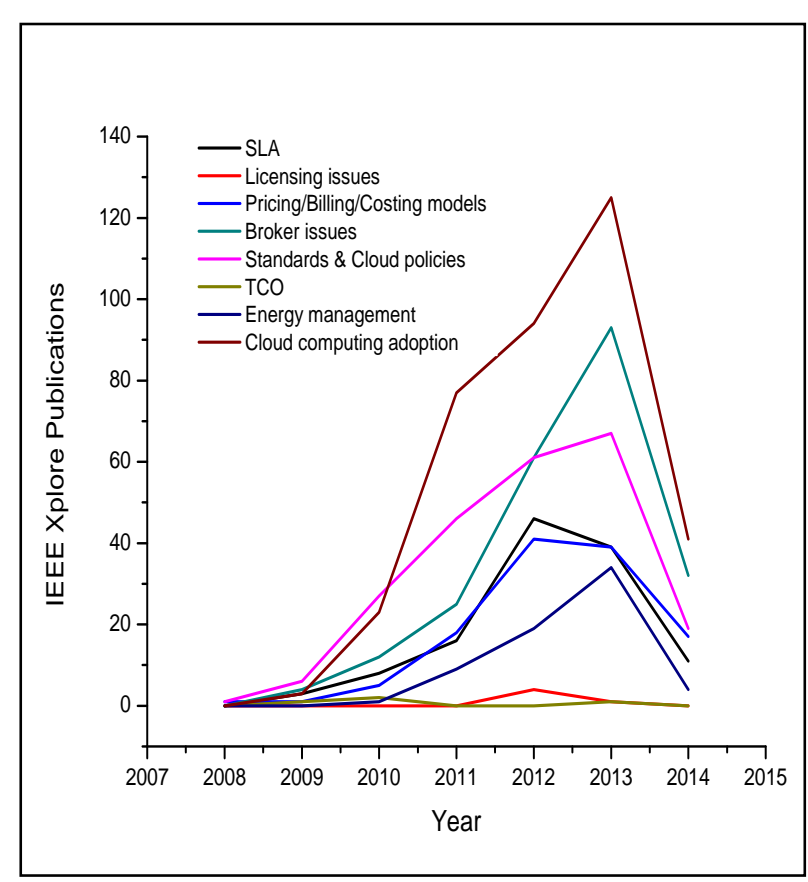

Fig.9. Research trend of Cloud Computing - Business Aspects in IEEE Xplore.

Table 6. Comparison between Technical and Business Aspects Research Studies (IEEE Xplore Publications)

\begin{tabular}{|l|l|l|}
\hline Year & $\begin{array}{l}\text { Technical Aspects } \\
\text { (\% of Study) }\end{array}$ & $\begin{array}{l}\text { Business Aspects } \\
\text { (\% of Study) }\end{array}$ \\
\hline 2008 & 88.89 & 11.11 \\
\hline 2009 & 89.53 & 10.47 \\
\hline 2010 & 89.54 & 10.46 \\
\hline 2011 & 86.30 & 13.70 \\
\hline 2012 & 84.75 & 15.25 \\
\hline 2013 & 85.18 & 14.82 \\
\hline 2014 & 88.77 & 11.23 \\
\hline
\end{tabular}

\section{B. Gartner Startegic Technology List}

Gartner group is an icon to its corporate clients however it has only limited attention by academics. Every year Gartner publishes list of top 10 strategic technologies available at [89]. The strategic technology list is prepared based on hype-cycles, surveys, client inquiries and ongoing research. Trend of cloud computing is analyzed using Gartner strategic technologies from year 2004 to 2014 .

Cloud computing and/or it's enablers are present 33 times out of 110 in Gartner strategic technology list from year 2004 to 2014 .

In 2005 and 2008 Gartner strategic technology list contains two technologies whose name is not cloud computing but the underlying philosophy is similar to cloud. 
- Static and Unshared Island, Real-Time Enterprise (RTE) Infrastructure (2005)

- Web Platform \& WOA (2008)

Year 2013 and 2014 shows cloud computing technology in different forms.

- Personal Cloud (2013) - The personal cloud will entail the unique collection of services, Web destinations and connectivity that will become the home of their computing and communication activities. Users will see it as a portable, alwaysavailable place where they go for all their digital needs.

- The Era of Personal Cloud (2014) - The personal cloud era will mark a power shift away from devices toward services.

- Hybrid IT and Cloud Computing / Hybrid Cloud and IT as Service Broker (2013, 2014) -Emerging as IT organizations to help improve the provisioning and consumption of inherently distributed heterogeneous and often complex cloud services for their internal users and external business partners.

- Cloud/Client Architecture (2014) - In the cloud/client architecture, the client is a rich application running on an Internet-connected device and the server is a set of application services hosted in an increasingly elastically scalable cloud computing platform. The client environment may be a native application or browser-based; the increasing power of the browser is available to many client devices, mobile and desktop alike.

- Web Scale IT (2014) - Web-scale IT is a pattern of global-class computing that delivers the capabilities of large cloud service providers within an enterprise IT setting by rethinking positions across several dimensions.

\section{CONCLUSIONS}

Cloud computing is one of the transformational technology in the computing world. Cloud computing driven data centers and services helping organizations to leverage multiple business attributes like cost, reliability, ease of acquiring and maintaining technology systems are in ascend.

This paper forecast cloud computing technology and cloud computing industry in India using strengths, weaknesses, opportunities and threats as a tool. Cloud computing provides good solutions to increase productivity of organization in many respects such as cost effectiveness, reduction in efforts and time etc. The major limitations reported by many researchers are regarding security, privacy, compatibility and interoperability. The research trends in IEEE Xplore show that many researchers are working on weakness and threats arise from technical problems. Results show that increasing efforts are required to improve the business issues from different aspects such as service level agreement, licensing issues, adoption framework, pricing and billing issues etc.

Cloud computing technology has received very good support from governments, giant software and hardware companies, researchers and customers. This analysis shows that cloud computing has upwards trend and it will influence enterprises in coming years.

Cloud technology is changing rapidly due to market competition and in near future it shall metamorphosis into personal cloud, cloud/client architecture, hybrid cloud computing and IT. We also envisage newer solutions will be emerging in securing information in cloud computing enabled Data Centre's through virtualization.

Future work need to be investigating to identifying best fit of cloud computing technologies in E-governance and business sectors like, Energy, Education, Micro finance and Health care.

\section{REFERENCES}

[1] R. Buyya, C. Vecchiola, and S. T. Selvi, "Mastering cloud computing: foundations and applications programming," 2013.

[2] P. K. Paul, K. Kumar, and D. Chaterjee, "Cloud computing emphasizing emerging possibilities to the entire Information Infrastructure," Trends in Information Management (TRIM), vol. 9, no. 2, 2014.

[3] R. El-Gazzar, "A Literature Review on Cloud computing Adoption Issues in Enterprises," IFIP Advances in Information and Communication Technology, vol. 429, pp. 214-242, 2014.

[4] http://press.ihs.com/press-release/design-supplychain/cloud-related-spending-businesses-triple-20112017, Accessed April 2015.

[5] Worldwide Cloud Computing Market Shares, Strategies, and Forecasts, 2009-2015, Retrieved from: http://www.researchandmarkets.com/reports/1057978/w orldwide_cloud_computing_market_shares, December, 2014.

[6] Australian Government-Department of Broadband, Communications and the Digital Economy, "The National Cloud Computing Strategy,” May, 2013.

[7] W. Kim, S. D. Kim, E. Lee, and S. Lee, "Adoption issues for cloud computing," In Proceedings of the 7th International Conference on Advances in Mobile Computing and Multimedia, pp. 2-5, ACM, December 2009.

[8] JRC European Commission, "SWOT Analysis," For Learn Project, 2010. [Online]. Available: http://forlearn.jrc.ec.europa.eu/guide/4_methodology/me th_swot-analysis.htm.

[9] M. Lobo and P. Khanna, "Cloud Computing: The Silver Lining," International Journal of Computer Applications, vol. 56, no. 9, 2012.

[10] S. Marston, Z. Li, S. Bandyopadhyay, J. Zhang, and A. Ghalsasi, "Cloud computing- The business perspective," Decision Support Systems, vol. 51, no.1, pp.176-189, 2011.

[11] S. Cole, D. Van Hertem, L. Meeus, and R. Belmans, "SWOT analysis of utility side energy storage technologies," $5^{\text {th }}$ WSEAS / IASME international conference on electric power systems, high voltages, electric machines, pp. 16-18, 2005. 
[12] J. Jandebeur, J Cho, S. E Lee, and A. Schaeufele, "SWOT analysis of near field communication technology," Proceedings of Academic and Business Institute International Conference, 2013.

[13] P. Mell and T. Grance, "The NIST definition of Cloud computing," NIST Special Publication, 2011.

[14] I. Foster, Y. Zhao, I. Raicu, and S. Lu, "Cloud computing and grid computing 360-degree compared," In Grid Computing Environments Workshop, 2008. GCE'08, pp. 1-10. IEEE, 2008.

[15] L. Youseff, M. Butrico, and D. Silva, "Toward a unified ontology of Cloud computing," In Grid Computing Environments Workshop, 2008, GCE'08, pp. 1-10, IEEE, 2008.

[16] VMware, "CIO Global Cloud computing Adoption Survey Results," January 2011.

[17] Open Group, "Cloud ROI Survey Results Comparison 2011 and 2012," 2012.

[18] "Business Cloud: The State of Play Shifts Rapidly, Fresh Insights into Cloud Adoption Trends," Report Capgemini 2012.

[19] J. Harris and A. Alter, "Cloudrise: Rewards and Risks at the Dawn of Cloud computing," Accenture Institute for High Performance Research Report, pp. 5-30, November 2010.

[20] 1105 Government Information Group Research Study, "Cloud computing Research Study," 2010.

[21] IT Pro Cloud Survey Results, "Cloud computing survey: The Results," Microsoft Technet, 2011.

[22] IBM Academy of Technology Survey, "Cloud computing insights from 110 implementation projects," IBM Academy of Technology Thought Leadership White Paper, October, 2010

[23] Deloitte and CIOnet, "Cloud Adoption Study: Cloud computing is gaining momentum," 2011.

[24] M. Bohm, S. Leimeister, C. Riedl, and H. Krcmar, "Cloud Computing and Computing Evolution," Cloud Computing Technologies, Business Models, Opportunities and Challenges, CRC Press, pp. 1-25, 2011.

[25] A. Apostu, F. Puican, G. Ularu, G. Suciu, and G. Todoran, "New Classes of Applications in the Cloud. Evaluating Advantages and Disadvantages of Cloud Computing for Telemetry Applications," Database Systems Journal, vol.5, no.1, March 2014.

[26] V. Rajaraman, “Cloud Computing," Resonance, vol.19, no. 3, pp. 242-258, 2014.

[27] G. Demarest and R. Wang, "Oracle Cloud Computing," An Oracle White Paper, May 2010.

[28] M. Pandya, "Cloud computing for libraries: A SWOT analysis," 8th Convention PLANNER-2012 Sikkim University, Gangtok, pp. 387-394, 2012.

[29] S. Wattal and A. Kumar, "Cloud Computing - An Emerging Trend in Information Technology," IEEE International Conference on Issues and Challenges in Intelligent Computing Techniques (ICICT), 2014.

[30] "Benefits of SaaS," Available at: http://www.salesforce.com/in/saas/benefits-of-saas/, Accessed 06 Feb. 2015.

[31] "5 Reasons to Consider SaaS for Your Business Applications," QuinStreet Inc., 2013.

[32] S. Frost and Sullivan, "Jumping into the PaaS Pool: Why Platform as a Service is the Next Hot Cloud Service," An Excerpt from Cloud Computing, vol. 2, no. 2, May 2012.

[33] V. Delgado, "Exploring the limits of cloud computing," Master's thesis, Kungliga Tekniska Högskolan,
Stockholm, Sweden, 2010

[34] K. Ghaffari, M. S. Delgosha, and N. Abdolvand, "Towards Cloud Computing: A SWOT Analysis on its Adoption in SMEs," arXiv preprint arXiv: 1405.1932, 2014.

[35] Cloud Standards Coordination, Available at: http://www.etsi.org/images/files/Events/2013/2013_CS C_Delivery_WS/CSC-Final_report-013-

CSC_Final_report_v1_0_PDF_format-.PDF, Accessed 7 May 2015

[36] "Cloud Security Standards: What to Expect \& What to Negotiate," Cloud Standards Customer Council. Available at: http://www.cloudcouncil.org/Cloud_Security_Standards_Landscape_Fina 1.pdf, Accessed 7 May 2015.

[37] RightScale Inc., "Cloud Pricing Trends," White Paper, 2014.

[38] "The Cloud Changing the Business Ecosystem," KPMG, 2011.

[39] Secure 24, Available at: http://www.secure-24.com/3innovations-to-look-out-for-after-cloud-computing/, Accessed: 7/5/2015.

[40] http://www.gartner.com/newsroom/id/2613015, accessed 9 May 2015.

[41] CtrlS, "State of Cloud Adoption In India", Available at: http://www.ctrls.in/blog/cloud-adoption-in-india/, Accessed 9 May 2015.

[42] "Activities and Achievements," Department of Electronics \& Information Technology (DeitY) 2014. Available at: http://deity.gov.in/sites/upload_files/dit/files/activities_a nd_achievements_of_deity_2014.pdf, accessed 31 December 2014.

[43] EY, "Cloud Computing Adoption in India". Available at:http://www.ey.com/IN/en/Industries/Technology/Clou d-computing-adoption-in-India, Accessed 9 May 2015.

[44] J. Yang and Z. Chen, "Cloud computing research and security issues," International Conference on Computational Intelligence and Software Engineering (CiSE), pp. 1-3, 2010.

[45] W. Dawoud, I. Takouna, and C. Meinel, "Infrastructure as a service security: Challenges and solutions," $7^{\text {th }}$ International Conference on Informatics and Systems, pp. 1-8, 2010.

[46] A. Behl, "Emerging security challenges in Cloud computing: An insight to Cloud security challenges and their mitigation," in Information and Communication Technologies (WICT), 2011 World Congress on, pp. 217-222, 2011.

[47] F. Simorjay and J. Jones, "Trends in Cloud Computing: Cloud Security Readiness Tool," Microsoft Corporation, 2013.

[48] J. Staten, "Is Cloud Computing Ready For The Enterprise," Forrester Research, March 7, 2008.

[49] S. Sengupta, V. Kaulgud, and V. Sharma, "Cloud Computing Security-Trends and Research Directions," IEEE World Congress on Services, Washington, DC, pp. 524-531, 2011

[50] Z. Xin, L. Song-qing and L. Nai-wen, "Research on Cloud Computing Data Security Model Based on Multidimension," International Symposium on Information Technology in Medicine and Education, vol. 2, pp. 897900, 2012.

[51] A. Ibrahim, J. Hamlyn-Harris, and J. Grundy, "Emerging Security Challenges of Cloud Virtual Infrastructure," The Asia Pacific Cloud Workshop Sydney, Australia, 2010. 
[52] C. Xu, Q. Tian, and H. Zhang, "A Research of Safety Mechanism in Cloud Computing Platform Based on Virtualization," $7^{\text {th }}$ International Conference on Computer Science \& Education (ICCSE 2012) July 1417, 2012, Melbourne, Australia, 2012.

[53] N. Gonzalez, C. Miers, F. Redigolo, M. Simplicio, T. Carvalho, M. Näslund, and M. Pourzandi, "A quantitative analysis of current security concerns and solutions for Cloud computing," Journal of Cloud Computing: Advances, Systems and Applications, 2012.

[54] S. Hashemi and A. Bardsiri, "Cloud Computing Vs. Grid computing," ARPN Journal of Systems and Software, vol. 2, no.5, May 2012.

[55] C. Wang, Q. Wang, K. Ren, and W. Lou, "Ensuring Data Storage Security in Cloud Computing," $17^{\text {th }}$ International workshop on Quality of Service, pp.1-9, July 13-15, 2009.

[56] E. Gorelik, "Cloud computing models," Doctoral dissertation, Massachusetts Institute of Technology, 2013.

[57] I. Sokolov, "Cloud Computing: Overview, Concepts and Business Deployment Scenarios,” Doctoral dissertation, Bachelor's thesis, Vienna University of Economics and Business, Austria, 2009.

[58] R. Saleem, "Cloud Computing's Effect on Enterprises in terms of cost and security," Doctoral dissertation, Master Thesis (Lund University), Lund, 2011.

[59] M. Zhou, R. Zhang, W. Xie, W. Qian, and A. Zhou, "Security and Privacy in Cloud Computing: A Survey," $6^{\text {th }}$ International Conf. on Semantics Knowledge and Grid (SKG), Ningbo, China, pp. 105-112, Nov. 2010.

[60] G. Zhang, Y. Yang, X. Zhang, C. Liu, and J. Chen, "Key research issues for privacy protection and preservation in Cloud computing," $2^{\text {nd }}$ International Conference on Cloud and Green Computing, pp. 47-54, 2012.

[61] C. Bulla, S. Bhojannavar, and V. Danawade, "Cloud Computing: Research Activities and Challenges," International Journal of Emerging Trends \& Technology in Computer Science, vol. 2, issue 5, SeptemberOctober 2013.

[62] Intel IT Center, "Planning Guide: Virtualization and Cloud Computing," August 2013.

[63] Z. He and G. Liang, "Research and Evaluation of Network Virtualization in Cloud Computing Environment," International conference on Networking and Distributed Computing (ICNDC), IEEE, pp. 40-44, 2012.

[64] Q. Zhang, L. Cheng and R. Boutaba, "Cloud Computing: State of the art and Research Challenges," Journal of Internet Services and Applications, vol. 1, pp. 7-18, 2010.

[65] M. Nazir, "Cloud Computing: Overview and Current Research Challenges," IOSR Journal of Computer Engineering, vol. 8, issue 1, pp. 14-22, 2012.

[66] I. Iyoob, "Cloud Computing: Survey of Optimization Problems," Georgia Institute of Technology, February $15,2013$.

[67] S. Subashini and V. Kavitha, "A survey on security issues in service delivery models of Cloud computing," Journal of Network and Computer Applications, 2011.

[68] R. Chang, J. Gao, V. Gruhn, J. He, G. Roussos, and W. Tsai, "Mobile Cloud Computing Research- Issues, Challenges, and Needs," IEEE 7th International Symposium on Service Oriented System Engineering, pp. 442-453, 2013.

[69] D. Dev and K. Baishnab, "A Review and Research towards Mobile Cloud Computing," 2nd IEEE International Conference on Mobile Cloud Computing, Services, and Engineering, pp. 252-256, 2014.

[70] H. Qi and A. Gani, "Research on Mobile Cloud Computing: Review, Trend and Perspectives," $2^{\text {nd }}$ International Conference on Digital Information and Communication Technology and its Applications (DICTAP), IEEE, pp. 195-202, 2012.

[71] L. Guan, X. Ke, M. Song, and J. Song, "A Survey of Research on Mobile Cloud Computing," 10 $10^{\text {th }}$ IEEE / ACIS International Conference on Computer and Information Science, pp. 387-392, 2011.

[72] N. Fernando, S. Loke, and W. Rahayu, "Mobile Cloud computing: A survey," Future Generation Computer Systems, vol. 29, no. 1, pp. 84-106, 2013.

[73] M. Armbrust, A. Fox, R. Griffith, A. Joseph, R. Katz, A. Konwinski, G. Lee, D. Patterson, A. Rabkin, I. Stoica, and M. Zaharia, "A View of Cloud Computing," Communications of the ACM, vol. 53, no. 4, 2010.

[74] F. Satoh, H. Yanagisawa, H. Takahashi, and T. Kushida, "Total Energy Management System for Cloud Computing," IEEE International Conference on Cloud Engineering, pp. 233-240, 2013.

[75] S. Habib, S. Ries, and M. Muhlhauser, "Cloud Computing Landscape and Research Challenges Regarding Trust and Reputation," Symposia and Workshops on ATC/UIC, pp. 410-415, 2010.

[76] S. Kuyoro, F. Ibikunle and O. Awodele, "Cloud Computing Security Issues and Challenges," International Journal of Computer Networks, vol. 3, issue 5, 2011.

[77] A. Stanik, M. Koerner, and L. Lymberopoulos, "SLAdriven Federated Cloud Networking: Quality of Service for Cloud based Software Defined Networks," Procedia Computer Science, vol. 34, pp. 655-660, 2014.

[78] R. Panigrahi, M. Ghose, and M. Pramanik, "Cloud Computing: A new Era of Computing in the Field of Information Management," International Journal of Computer Science Engineering, vol. 2, no. 5, Sept. 2013.

[79] M. Al-Roomi, S. Al-Ebrahim, S. Buqrais, and I. Ahmad, "Cloud Computing Pricing Models: A Survey," International Journal of Grid and Distributed Computing, vol.6, no.5, pp.93-106, 2013.

[80] S. Nair, S. Porwal, T. Dimitrakos, A. Ferrer, J. Tordsson, T. Sharif, C. Sheridan, M. Rajarajan, and A. Khan, "Towards Secure Cloud Bursting, Brokerage and Aggregation," $8^{\text {th }}$ IEEE European Conference on Web Services (ECOWS 2010), pp. 189-196, 2010.

[81] X. Li, Y. Li, T. Liu, J. Qiu, and F. Wang, "The Method and Tool of Cost Analysis for Cloud Computing," IEEE International Conference on Cloud Computing, pp. 93100, 2009.

[82] E. Yeboah-Boateng and K. Essandoh, "Factors Influencing the Adoption of Cloud Computing by Small and Medium Enterprises (SMEs) in Developing Economies," International Journal of Emerging Science and Engineering, vol. 2, no. 4, pp. 13-20, February 2014.

[83] R. Bedward and D. Fokum, "A Cloud Computing Adoption Approach for Jamaican Institutions," IEEE SOUTHEASTCON, 2014.

[84] L. Morgan and K. Conboy, "Factors Affecting the Adoption of Cloud Computing: An Exploratory Study," $21^{\text {st }}$ European Conference on Information Systems, 2013.

[85] H. Borgman, B. Bahli, H. Heier, and F. Schewski, "Cloudrise: Exploring Cloud Computing Adoption and Governance with the TOE Framework," 46 ${ }^{\text {th }}$ Hawaii 
International Conference on System Sciences, pp. 44254435, 2013.

[86] K. Sun and Y. Li, "Effort Estimation in Cloud Migration Process," IEEE $7^{\text {th }}$ International Symposium on Service Oriented System Engineering, pp. 84-91, 2013.

[87] M. Stieninger, D. Nedbal, W. Wetzlinger, G. Wagner, and M. Erskine, "Impacts on the Organizational Adoption of Cloud Computing: A Reconceptualization of Influencing Factors," CENTERIS 2014, Procedia Technology, vol. 16, pp. 85-93, 2014.

[88] S. Bharadwaj and P. Lal, "Exploring the Impact of Cloud Computing Adoption on Organizational Flexibility: A Client Perspective," International Conference on Cloud Computing Technologies, Applications and Management (ICCCTAM), pp. 121131, 2012.

[89] http://www.gartner.com/newsroom/id/

\section{Authors' Profiles}

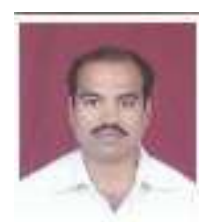

Amol C. Adamuthe received Master of Technology in Computer Engineering from Dr. B. A. Technological University, Lonere, MS, India in 2008. He is currently an Assistant Professor at Rajarambapu Institute of Technology, Sakharale, Sangli, MS, India. His technical fields today are technology forecasting, cloud computing.

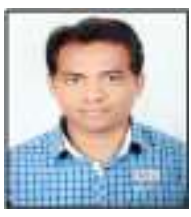

Vikram D. Salunkhe is pursuing his M.Tech at the Department of Computer Science and Engineering at Rajarambapu Institute of Technology, Maharashtra (India). His research interests include cloud computing and technology forecasting.

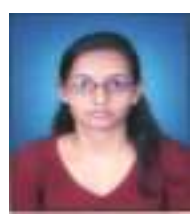

Seema H. Patil is pursuing her M.Tech at the Department of Computer Science and Engineering at Rajarambapu Institute of Technology, Maharashtra (India).Her research interests include cloud computing and technology forecasting.

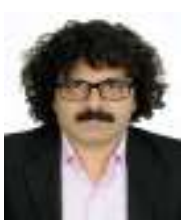

Gopakumaran T. Thampi received the degree of Ph.D. in Technology from Mumbai University, MS, India in 2004. He is currently a Professor and Principal at Thadomal Shahani Engineering College, Mumbai, MS, India. His area of interests are related to business process re-engineering in the realm of engineering education, integration of enterprise softwares like ERP, CRM \& cloud technology and integration of hardware \& software technology in enterprise setting for cost and quality arbitrage in global market. He is author of three books. He has guided 6 Ph.D., $8 \mathrm{M}$. Phil and more than 20 M.E. students.

How to cite this paper: Amol C. Adamuthe, Vikram D. Salunkhe, Seema H. Patil, Gopakumaran T. Thampi,"Cloud Computing - A market Perspective and Research Directions", International Journal of Information Technology and Computer
Science(IJITCS), vol.7, no.10, pp.42-53, 2015. DOI: 10.5815/ijitcs.2015.10.06 